\title{
Special Topic: Cretaceous greenhouse palaeoclimate and sea-level changes
}

Earth's climate has oscillated between greenhouse (warm) and icehouse (cold) modes throughout Earth history. At present, Earth is in the midst of an icehouse climate interval, despite the anthropogenic contribution to global warming and sea-level rise due to industrialization during the past two centuries. This led to a dramatic increase in atmospheric $\mathrm{CO}_{2}$, mainly caused by the extensive burning of fossils fuels. The Cretaceous (145 to 66 million years ago) is the youngest prolonged greenhouse climate interval in the Phanerozoic, marked by very high global mean temperatures with some extreme warming peaks ('hothouse' or 'supergreenhouse'), largely absence of permanent continental ice sheets, a mean global sea-level having been some $250 \mathrm{~m}$ higher than that of today, and levels of carbon dioxide 4 to 10 times higher than those of the pre-industrial era. If temperature will continue to rise as quickly as in the last three decades, we are close to being at the cusp to a new greenhouse climate interval facing quickly rising global sea-level and reaching atmospheric $\mathrm{CO}_{2}$ levels of the 'Cretaceous supergreenhouse' in about the years 2190-2260 (Hay, 2011). Evidence from Earth's history indicates that glacial-interglacial climate mode changes as well as past sea-level changes such as in the Cretaceous greenhouse occurred at rates orders of magnitude slower than observed at present.

The recent rise in global sea-level in response to rising levels of atmospheric greenhouse gases, the associated global warming, and the waning of continental ice shields is a primary concern for human society. To predict future sea-levels we need a better understanding of the record of past sea-level changes, especially in the greenhouse palaeoclimate modes. Therefore, understanding the Cretaceous palaeoclimate is essential for a more accurate prediction of future global climate, sea-level rise and environmental changes in a prospective 'Cretaceous-like' greenhouse Earth.

\section{Section topic introduction}

The UNESCO/IUGS International Geoscience Programme (IGCP) Project 609 (http://www.univie.ac.at/igcp609/) addresses correlation, causes and consequences of significant short-term sea-level changes during the last major greenhouse episode of Earth history, the Cretaceous. Mechanisms of shorter-term, 3rd to 4th order (kyr to 100s of kyr), sea-level changes recorded in sedimentary archives of Mesozoic Greenhouse climate are controversial and include inferred brief glacial episodes, storage and release of groundwater, and regional tectonics and mantle-induced processes such as dynamic topography. Based on improvements in the Geological Time Scale, especially the evaluation of astrochronology in the Cretaceous, it is now for the first time possible to correlate and date short-term Cretaceous sea-level records with a resolution appropriate for their detailed analysis.

The International Workshop "Climate and Environmental Evolution in the Mesozoic Greenhouse World" and the 3rd IGCP 609 Workshop "Cretaceous Sea-Level Change" were jointly held at Nanjing University in Nanjing, China during September 5-11, 2015. Forty one participants from 10 countries (Austria, China, Egypt, Japan, Nepal, New Zealand, Pakistan, Russia, Slovak Republic, USA) participated in this meeting (Figure 1). This workshop received 38 abstracts; among them 28 were given as oral presentation (including 3 IGCP project talks and 3 invited scientifical talks) and 4 were poster presentations. The workshop was followed by a 4-day field trip (Figure 2). The objective of this workshop was to review the progress and new data on studies of Cretaceous sea-level change, as well as climate and environmental evolution in the Mesozoic Greenhouse World.

Citation: $\quad \mathrm{Hu}$ X M, Wagreich M, Sames B. 2017. Special Topic: Cretaceous greenhouse palaeoclimate and sea-level changes. Science China Earth Sciences, 60: 1-4, doi: $10.1007 / \mathrm{s} 11430-016-0278-3$ 


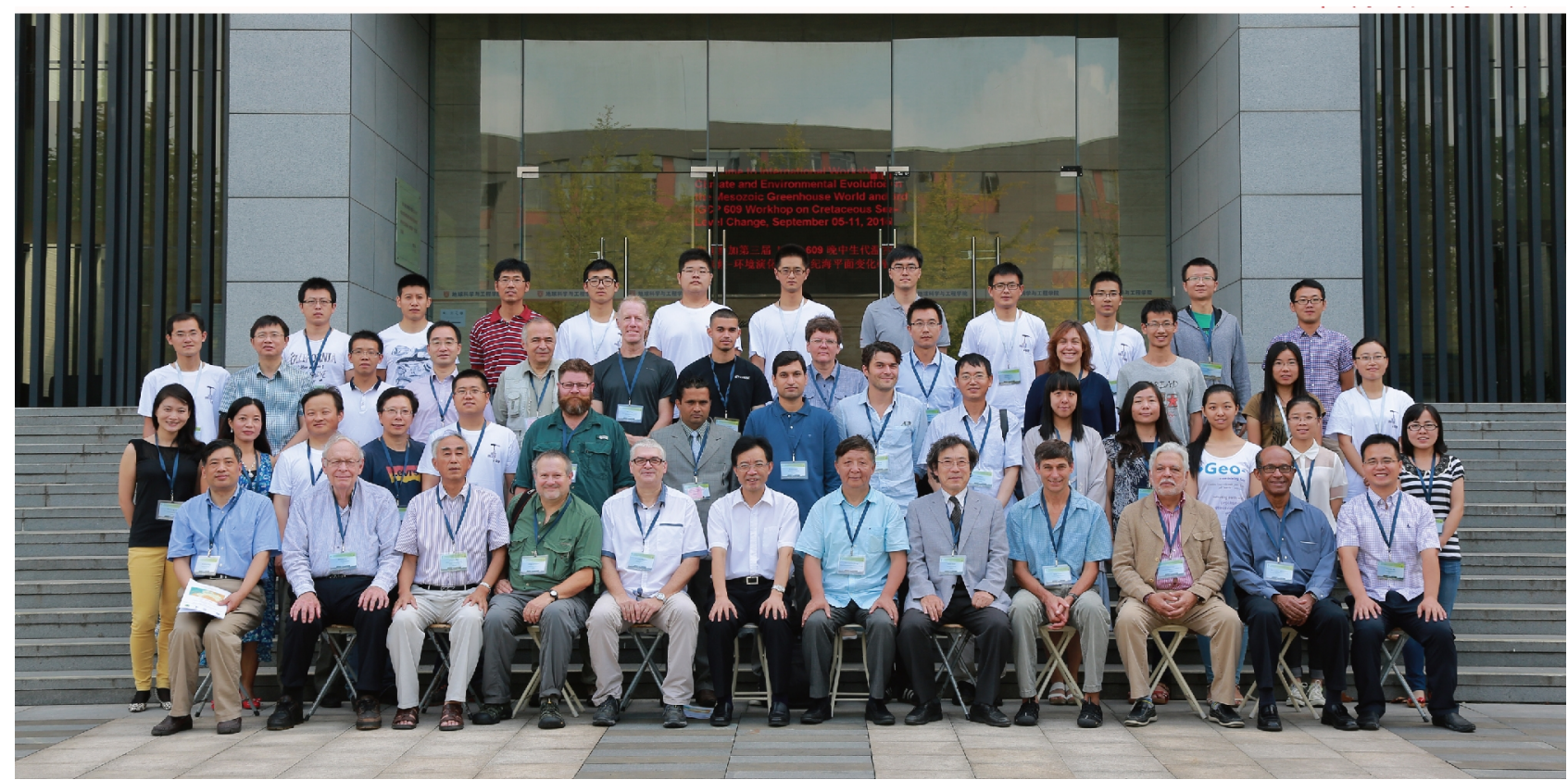

Figure 1 Group photo of the workshop participants in front of the School of Earth Science and Engineering, Nanjing University.

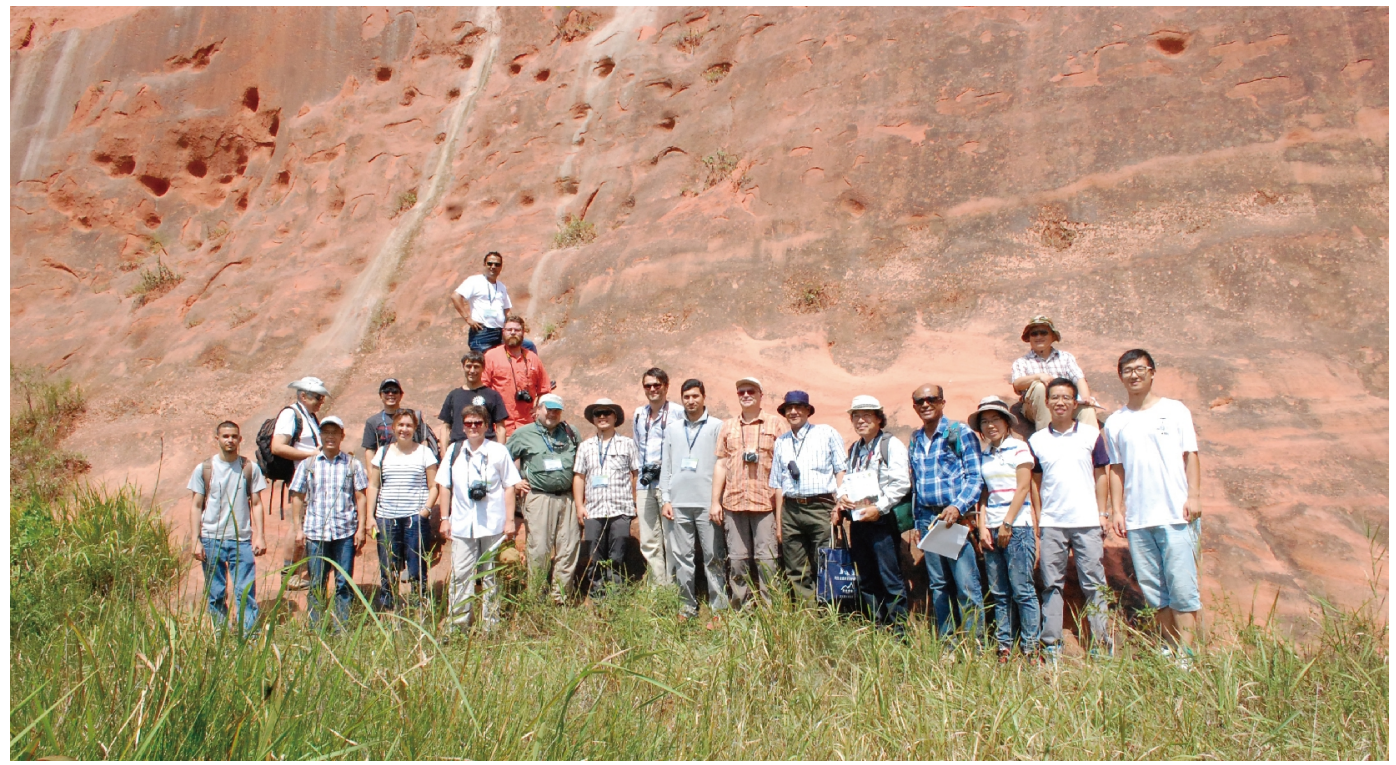

Figure 2 The field trip participants in front of the aeolian sandstones of the Upper Cretaceous Chishan Formation, south of Nanjing City.

Five scientific sessions were held including: 1) IGCP Projects Introductions; 2) Cretaceous Sea-Level Change; 3) Mesozoic Climate and Environmental Changes; 4) Mesozoic Terrestrial Environments and Geobiological Evolution; 5) Mesozoic Abrupt Palaeoenvionmental Change and Major Geological Events.

Following the proceedings volume of the joint 2nd UNESCO-IUGS IGCP 609 and ESF EEARTHTIME-EU Sequence Stratigraphy Workshop that took place in Bucharest, Romania 2014 (Wagreich et al., 2016), this special section of Science China Earth Sciences addresses further advances and perspectives on Cretaceous short-term climate and sea-level change (IGCP 609) and not only includes papers having been discussed and presented during the meeting in Nanjing, 2015 but also from other authors participating in IGCP 609. This selection comprises six papers including two overview papers by renowned specialists in the field (Hay; Haq and Huber). One gives an updated overview on the Cretaceous climate and related long-discussed problems, and the second focuses on the discussion of a sequence boundary representing a major sea-level fall during the hottest greenhouse (also Cretaceous 'hothouse', Cenomanian-Turonian) interval. The other papers are case studies focusing on oceanic anoxic events 
including OAE1a, OAE1b, and OAE1d during the mid-Cretaceous time interval, and on palaeohydrology of mid-Cretaceous palaeosols. Thus, this compiled section within the scope of IGCP 609 combines up-to-date contributions to the understanding of Cretaceous greenhouse climate and short-term eustatic sea-level changes.

\section{Overview of papers}

William W. Hay (Hay, 2017 this issue), following his recent, highly cited overview papers, presents an updated review on Cretaceous greenhouse climate. In this comprehensive overview paper, he addresses ten major topics related to Cretaceous greenhouse climate reconstruction, including (1) the shape of the Cretaceous Earth, (2) the cold continental interior paradox, (3) the sea-level problem; (4) causes of sea-level changes, (5) the greenhouse gas problem, (6) the hydrological problem, (7) climate models, (8) the temperature problem, (9) atmosphere and oceanic circulation, and (10) land surface conditions. Hay concludes that new data and ideas are changing our view of conditions during the Cretaceous and a major rethinking of the nature of conditions on a warmer Earth is underway.

Short-term eustasy has generally been considered as being a consequence of the growth and decay of continental ice sheets that would explain large, rapid changes in sea level, even during periods of relative global climatic warmth. However, such a mechanism has become increasingly difficult to envision during times of extreme global warmth such as the Turonian, when the equator-to-pole temperature gradient was very low and the presence of polar ice seems improbable (Sames et al., 2016). Bilal U. Haq and Brian T. Huber (Haq and Huber, 2017 this issue) investigate the timing and extent of sea-level falls during the late Cenomanian through Turonian, and discuss in detail a major sequence boundary KTu4 represented by a widespread third-order sea-level fall centered around 91.8 Ma with a potential error range of 0.4 Ma during the Turonian hot greenhouse climate interval. They suggest that this major sea-level fall is very unlikely to have been controlled by continental ice volume fluctuations. They suggest that sea-level fluctuations during greenhouse times are due to a combination of several factors, such as the transfer of ground water into the ocean (Wendler and Wendler, 2016), entrainment and release of water from the mantle to the oceanic container, influencing eustasy rather than one dominant source.

Fluctuations in the carbon cycle is one of the hottest topics in deep-time climate research. Jander Socorro, Florentin J.M. R. Maurrasse, and Yosmel Sanchez-Hernandez (Socorro et al., 2017 this issue) study the C2 segment of the Early Aptian OAE1a, one of the global oceanic anoxic events in the Mesozoic, which represents a distinct carbon isotope negative anomaly of $\sim 1.8 \%$ to $\sim 2.23 \%$. Socorro et al. (2017) present a high-resolution organic geochemical study of the $\mathrm{C} 2$ interval in the El Pui section, Organyà Basin, Spain, including total organic carbon, total inorganic carbon, $\delta^{13} \mathrm{C}_{\mathrm{org}}, \mathrm{n}$-alkanes, microscopic analyses with petrographic microscope and SEM. One of the major findings of this paper is that the total inorganic carbon, the total organic carbon, the $\delta^{13} \mathrm{C}_{\mathrm{org}}$, microfacies, and the n-alkanes show no excursion, neither before, nor during, nor after the $\mathrm{C} 2$ negative inflection, indicating that local factors did not enhance the $\delta^{13} \mathrm{C}_{\text {org }}$ negative inflection during the $\mathrm{C} 2$ interval, thus reflecting a true change within the ocean carbon isotopic reservoir independently. Therefore they suggest that conjoint pulses of contemporaneous LIPs (Ontong Java) and massive explosive volcanism in northeast Asia (Songliao Basin), best conform to plausible causes of the negative intra-C2 carbon isotopic excursion (CIE) at that time.

Understanding of palaeoprecipitation and palaeohydrology in the climate system of the Cretaceous greenhouse world represents a major challenge in deep-time palaeoclimate research. Jeffrey Ross, Greg Ludvigson, Andreas Möller, Luis González, and J. D. Walker (Ross et al., 2017 this issue) use stable isotopic palaeohydrologic data from mid-Cretaceous palaeosols in North America to constrain the oxygen isotope mass balance of the Albian hydrologic cycle. Their results indicate that despite the orographic rain shadow effect, the processes of meridional atmospheric moisture transport in this locale were similar to those in more humid mid-latitude palaeoenvironments elsewhere in the North American Western Interior Basin.

Svetlana Zorina, Oksana Pavlova, Bulat Galiullin, Vladimir Morozov, Alexey Eskin (Zorina et al., 2017 this issue) present new data of mineral composition and microstructure of black shales associated with the Early Aptian OAE1a (Eastern Russian Platform) and the early Albian OAE1b (Middle Caspian). Black shales with pyrite framboids associated with OAE1a in the epicontinental sea-strait on the Eastern Russian Platform and with the OAE1b in the Middle Caspian on the NE margin of the Pery-Tethys, indicate euxinic (sulfidic) conditions with increased organic matter preservation.

Based on palynological assemblages from Albian-Cenomanian boundary sections in North Bulgaria, Polina Pavlishina (Pavlishina, 2017 this issue) discusses the response of the palynologic proxies, including dinoflagellate cysts and miospores, to change of the palaeo-redox environment. Based on dinocyst nutrient and productivity indices, a phase of enhanced nutrient availability and high primary productivity is inferred for the latest Albian interval. During the interval of the OAE1d, the abundance of peridinioid cysts indicates high primary productivity. However, from the pollen spectrum relatively stable vegetation patterns of surrounding continental areas during and after the Albian/Cenomanian boundary interval and OAE1d can be inferred. 
Acknowledgements We would like to thank the editor Prof. Fuyuan Wu for handling the papers for reviewing and publishing. We also appreciated the time and effort from the reviewers including Xi Chen (Beijing, China), David Batten (Manchester, UK), Andy Gale (Portsmouth, UK), Yuan Gao (Beijing, China), David J. Horne (London, UK), Jianguo Li (Nanjing, China), Xianghui Li (Nanjing, China), Yongxiang Li (Nanjing, China), Florentin Maurrasse (Miami, USA), Relu-Dumitru Roban (Bucharest, Romania), Stuart Robinson (Oxford, UK), Dmitry Ruban (Rostov-na-Donu, Russia), Marina Suarez (San Antonio, USA), Pujun Wang (Changchun, China). The first author acknowledges the financial support from the National Natural Science Foundation of China (NSFC) for Distinguished Young Scholar (Grant No. 41525007). This is an contribution to the IGCP609. This paper is a contribution of IGCP Project 609 "Climate-environmental deteriorations during greenhouse phases: Causes and consequences of short-term Cretaceous sea-level changes".

\section{References}

Haq B U, Huber B T. 2017. Anatomy of a eustatic event during the Turonian (Late Cretaceous) hot greenhouse climate. Sci China Earth Sci, 60: 20-29

Hay W W. 2017. Toward understanding Cretaceous climate-An updated review. Sci China Earth Sci, 60: 5-19

Hay W W. 2011. Can humans force a return to a 'Cretaceous' climate? Sedimentary Geol, 235: 5-26

Pavlishina P. 2017. Palynostratigraphy and palaeoenvironments around the Albian-Cenomanian boundary interval (OAE1d), North Bulgaria. Sci China Earth Sci, 60: 71-79

Ross J B, Ludvigson G A, Möller A, González L A, Walker J D. 2017. Stable isotope paleohydrology and chemostratigraphy of the Albian Wayan Formation from the wedge-top depozone, North American Western Interior Basin. Sci China Earth Sci, 60: 44-57

Sames B, Wagreich M, Wendler J E, Haq B U, Conrad C P, Melinte-Dobrinescu M C, Hu X, Wendler I, Wolfgring E, Yilmaz I Ö, Zorina S O. 2016. Review: Short-term sea-level changes in a greenhouse world-A view from the Cretaceous. Palaeogeogr Palaeoclimatol Palaeoecol, 441: 393-411

Socorro J, Maurrasse F J-M R, Sanchez-Hernandez Y. 2017. Characterization of the negative carbon isotope shift in segment C2, its global implications as a harbinger of OAE1a. Sci China Earth Sci, 60: 30-43

Wagreich M, Haq B U, Melinte-Dobrinescu M, Sames B, Yılmaz Ö. 2016. Advances and Perspectives in Understanding Cretaceous Sea-level Change. Palaeogeogr Palaeoclimatol Palaeoecol, 441: 391-392

Wendler J E, Wendler I. 2016. What drove sea-level fluctuations during the mid-Cretaceous greenhouse climate? Palaeogeogr Palaeoclimatol Palaeoecol, 441: $412-419$

Zorina S O, Pavlova O V, Galiullin B M, Morozov V P, Eskin A A. 2017. Euxinia as a dominant process during OAE1a (Early Aptian) on the Eastern Russian Platform and during OAE1b (Early Albian) in the Middle Caspian. Sci China Earth Sci, 60: 58-70

XiuMian HU

State Key Laboratory of Mineral Deposits Research, School of Earth Sciences and Engineering, Nanjing University, China E-mail: huxm@nju.edu.cn

Michael WAGREICH

Department of Geodynamics and Sedimentology, Center for Earth Sciences, University of Vienna, Austria E-mail: michael.wagreich@univie.ac.at

Benjamin SAMES

Department of Geodynamics and Sedimentology, Center for Earth Sciences, University of Vienna, Austria E-mail: benjamin.sames@univie.ac.at 